Article

\title{
Synthesis and Anticandidal Activity of New Imidazole-Chalcones
}

\author{
Derya Osmaniye ${ }^{1}$, Betul Kaya Cavusoglu1 ${ }^{1}$, Begum Nurpelin Saglik ${ }^{1,2}$, Serkan Levent ${ }^{1,2}$, \\ Ulviye Acar Cevik ${ }^{1,2}$, Ozlem Atli ${ }^{3}$, Yusuf Ozkay ${ }^{1,2, *}$ (i) and Zafer Asim Kaplancikli ${ }^{1}$
}

1 Department of Pharmaceutical Chemistry, Faculty of Pharmacy, Anadolu Universty, 26470 Eskişehir, Turkey; dosmaniye@anadolu.edu.tr (D.O.); betulkaya@anadolu.edu.tr (B.K.Ç.); bnsaglik@anadolu.edu.tr (B.N.S.); serkanlevent@anadolu.edu.tr (S.L.); uacar@anadolu.edu.tr (U.A.Ç.); zakaplan@anadolu.edu.tr (Z.A.K.)

2 Doping and Narcotic Compounds Analysis Laboratory, Faculty of Pharmacy, Anadolu Universty, 26470 Eskişehir, Turkey

3 Department of Pharmaceutical Toxicology, Faculty of Pharmacy, Anadolu Universty, 26470 Eskişehir, Turkey; oatli@anadolu.edu.tr

* Correspondence: yozkay@anadolu.edu.tr; Tel.: +90-222-335-0580 (ext. 3603)

Received: 23 March 2018; Accepted: 29 March 2018; Published: 4 April 2018

\begin{abstract}
In the present work, 15 new 1-(4-(1H-imidazol-1-yl)phenyl)-3-(4-substituedphenyl)prop-2en-1-one derivatives (3a-3o) were synthesized to evaluate their antifungal activity. Structures of newly synthesized imidazole derivatives (3a-3o) were characterized by $\mathrm{IR}^{1}{ }^{1} \mathrm{H}-\mathrm{NMR},{ }^{13} \mathrm{C}-\mathrm{NMR}$, and LCMSMS spectroscopic methods. The anticandidal activity of compounds (3a-3o) against $C$. albicans (ATCC 24433), C. krusei (ATCC 6258), C. parapsilosis (ATCC 22019), and C. glabrata (ATCC 90030) was elucidated according to the EUCAST definitive (EDef 7.1) method. Consistent with the activity studies, 3a-3d were found to be more potent derivatives with their MIC 50 values $(0.78 \mu \mathrm{g} / \mathrm{mL}-3.125 \mu \mathrm{g} / \mathrm{mL})$ against Candida strains. Compound $3 \mathrm{c}$ indicated similar antifungal activity to ketoconazole against all Candida species and was evaluated as the most active derivative in the series. Effects of the most potent derivatives 3a-3d on ergosterol biosynthesis were observed by LC-MS-MS method, which is based on quantification of the ergosterol level in C. krusei. Moreover, these compounds were subjected to a cytotoxicity test for the preliminary toxicological profiles and were found as non-cytotoxic. Furthermore, docking studies for the most active derivative $3 \mathrm{c}$ were performed to evaluate its binding modes on lanosterol 14- $\alpha$-demethylase. In addition to in vitro tests, docking studies also revealed that Compound $3 \mathrm{c}$ is a potential ergosterol biosynthesis inhibitor.
\end{abstract}

Keywords: imidazole; anticandidal activity; ergosterol inhibition; 14-alpha demethylase; docking study

\section{Introduction}

During the last few years, there has been an increased awareness of morbidity and mortality related to invasive and systemic fungal disease due to resistant fungi and immunocompromised infections such as AIDS. Candidiasis, aspergillosis, and cryptococcosis represent the three most common invasive fungal infections and have the highest mortality rates [1-3]. Cryptococcus, Trichosporon, Geotrichum, and Rhodotorula species also lead to diverse occurrence and restrict clinical therapy owing to the fungus variety. However, Candida species have been the primary reason of fungal infections [4,5]. Candida spp. are presently the third-to-fourth leading reason of bloodstream infections in the USA [6]. Candida is generally part of the normal flora of the mouth, vagina, skin, and intestinal tract and can exist in the oral cavity in $40-60 \%$ of the population without causing any problems $[7,8]$. If the environment of normal flora changes in a way that encourages fungal growth, Candida can 
increase and cause infections. Currently, various antifungal drugs have been used clinically in an attempt to reduce effects of fungal infections.

The "azoles" are class of antifungal agents whose molecules are based on a pharmacophore that inhibits the activity of fungal cytochrome P45014DM (also known as lanosterol 14- $\alpha$-demethylase, Erg11p, Cyp51p, and Erg16p). Azoles are administered against lanosterol 14- $\alpha$-demethylase in the ergosterol pathway. Antifungal azoles bind with nitrogen atoms to iron atoms of the heme group in the target protein and block fungal membrane ergosterol biosynthesis by inhibiting the demethylation of lanosterol to ergosterol and altering the fungal membrane structure and function [9-11]. The variability of azole nuclei is demonstrated in their present applications as pharmaceutical drugs used in the cure of bacterial, viral, and fungal infections, worm infestations, acid reflux, cancer, inflammations, and diabetes [12]. Imidazoles, the first group to be developed in azole antifungals also block the accumulation of methylated sterols, and disrupt the ergosterol biosynthesis, which is an essential component of the fungal cell wall. Moreover, some imidazole drugs, at high concentrations, could display a direct inhibitory effect on membranes, without intervene in sterols and sterol esters [13-15]. Ketoconazole, miconazole, and clotrimazole are some common drugs used for the treatment of patients affected by different Candida species [16-18]. Chemical structures of these antifungal agents are summarized in Figure 1 along with compounds targeted in the present study.

In other respects, it is well known that chalcones (1,3-diaryl-2-propen-1-one) plays an important role for anticandidal activity [19-22]. Their anticandidal action has been mainly related to the reactive enone moiety. As a Michael reaction acceptor, the enone unit binds thiol groups of certain proteins. Hence, most chalcones inhibit biosynthesis of the fungal cell wall and thus clarify their antifungal potential [23].

Knowledge of antifungal activities in both functional groups (azole and chalcone) has prompted curiosity about the antifungal effects of compounds containing these two groups. Therefore, within the scope of this study, a series of new imidazole-chalcone derivatives were synthesized and evaluated for their antifungal activities.

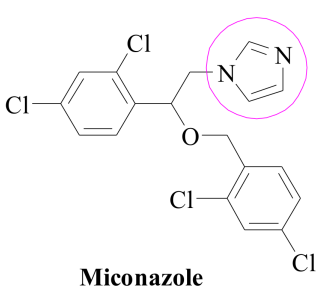

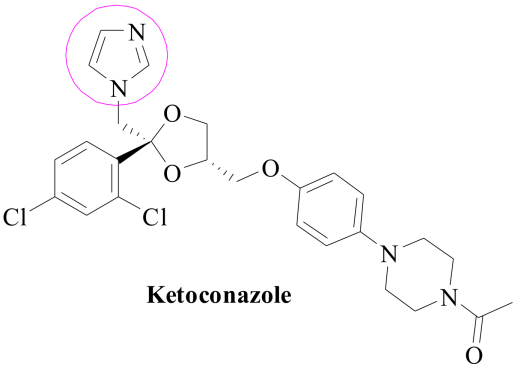

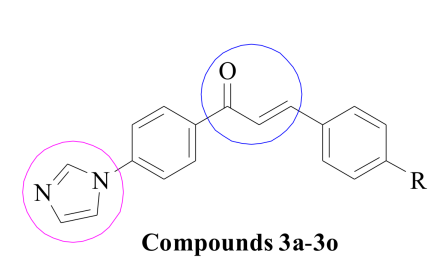

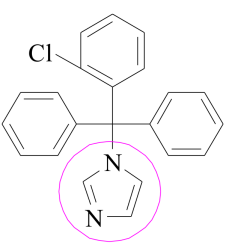

Clotrimazole

Figure 1. Structures of some antifungal agents and synthesized compounds (3a-3o).

\section{Results and Discussion}

\subsection{Chemistry}

Compounds 3a-3o were synthesized as summarized in Scheme 1. Initially, 4'-(imidazol-1-yl) acetophenone (1) was obtained under reflux by a reaction of 1-(4-fluorophenyl)ethan-1-one and $1 \mathrm{H}$-imidazole. Secondly, 4-fluorobenzaldehyde and appropriate proton donoring group were reacted 
in order to obtained 4-substitutedbenzaldehydes (2a-2o). In the last step, the target compounds (3a-3o) were synthesized by means of claisen schmidt condensation using $4^{\prime}$-(imidazol-1-yl)acetophenone (1) and appropriate 4-substituted benzaldehydes (2a-2o). IR, ${ }^{1} \mathrm{H}-\mathrm{NMR},{ }^{13} \mathrm{C}-\mathrm{NMR}$, and LCMSMS spectroscopic methods were used to perform structure elucidations of the final compounds. In the IR spectrum, $\mathrm{C}=\mathrm{O}$ and $\mathrm{C}=\mathrm{N}$ bonds were observed at $1601-1657 \mathrm{~cm}^{-1}$ and $1296-1389 \mathrm{~cm}^{-1}$, respectively. 1,4-Disubstituted benzene bands were observed at $808-814 \mathrm{~cm}^{-1}$. In the ${ }^{1} \mathrm{H}-\mathrm{NMR}$ spectrum, 1,4-disubstituted benzene protons had doublet peaks between 6.58 and 8.30 ppm. Three imidazole hydrogens gave broad singlet or triplet peaks with small coupling constant values at 7.16-7.17 ppm, 7.90-7.91 ppm, and 8.44-8.47 ppm. Vinyl protons were observed as two doublet peaks with coupling constant values, approximately $15 \mathrm{~Hz}$. In the ${ }^{13} \mathrm{C}-\mathrm{NMR}$ spectrum, aromatic peaks were gained between 113 and $161 \mathrm{ppm}$. Carbonyl carbon gave a peak over $187 \mathrm{ppm}$. Aliphatic carbons belonging to substituents were observed between 12 and 64 ppm. In the mass spectrum, all masses were matched with the expected $\mathrm{M}+\mathrm{H}$ values

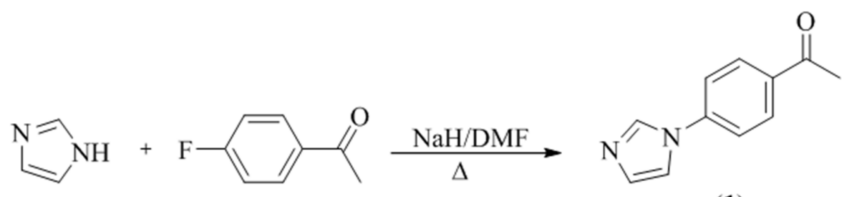

(1)

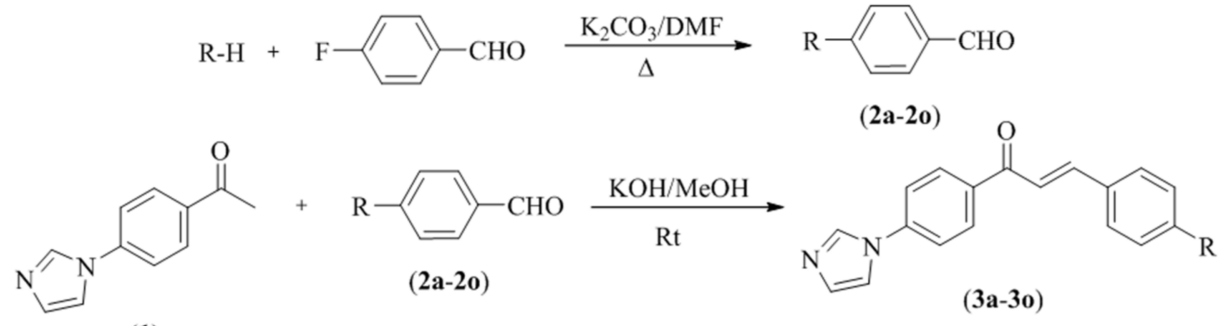

(1)

\begin{tabular}{|c|c|}
\hline Compounds & $\mathbf{R}$ \\
\hline $3 a$ & 4-methylphenoxy \\
\hline $3 b$ & 4-methylphenylthio \\
\hline $3 c$ & 4-methoxyphenoxy \\
\hline $3 d$ & 4-methoxyphenylthio \\
\hline $3 e$ & pyrrolidinyl \\
\hline $3 f$ & morpholinyl \\
\hline $3 g$ & piperidinyl \\
\hline $3 h$ & 3-methylpiperidinyl \\
\hline $3 \mathbf{i}$ & 4-methylpiperidinyl \\
\hline $3 \mathbf{j}$ & 3,5-dimethylpiperidinyl \\
\hline $3 k$ & 4-benzylpiperidinyl \\
\hline 31 & 4-methylpiperazinyl \\
\hline $3 m$ & 4-ethylpiperazinyl \\
\hline $3 n$ & 4-(2-dimethylaminoethyl)piperazinyl \\
\hline 30 & 4-(3-dimethylaminopropyl)piperazinyl \\
\hline
\end{tabular}

Scheme 1. Synthesis way of the target compounds (3a-3o).

\subsection{Antifungal Activity}

Synthesized compounds (3a-3o) were evaluated for anticandidal activity against C. albicans (ATCC 24433), C. krusei (ATCC 6258), C. parapsilosis (ATCC 22019), and C. glabrata (ATCC 90030). MIC 50 values were determined via fluorometric measurements, using resazurin solution [24,25]. Ketoconazole and fluconazole were used as a standard drug in the activity test. Anticandidal activity results are presented in Table 1. 
Consistent with the activity studies, Compounds $\mathbf{3 a}-\mathbf{3 d}$, were found to be more potent derivatives with their $\mathrm{MIC}_{50}$ values $(0.78-3.125 \mu \mathrm{g} / \mathrm{mL})$ against Candida strains. Compounds 3a-3c showed higher antifungal activity against $C$. krusei with an $\mathrm{MIC}_{50}$ value of $0.78 \mu \mathrm{g} / \mathrm{mL}$ compared with standard drugs. Furthermore, $\mathrm{MIC}_{50}$ value of $0.78 \mu \mathrm{g} / \mathrm{mL}$ was recorded for Compounds $3 \mathrm{c}$ and $3 \mathrm{~d}$ against C. glabrata. Compound $3 \mathrm{c}$ indicated similar antifungal activity to ketoconazole and fluconazole against all Candida species and was evaluated as the most active derivative in the series.

Antimicrobial activity results clearly indicated that variable groups at the 4th position of the phenyl moiety have an essential impact on antifungal activity. It was observed that the presence of more liphophilic phenoxy and phenylthio groups in Compounds $\mathbf{3 a - 3 \mathbf { d }}$ have significantly enhanced anticandidal activity when compared with the compounds that carry cyclic secondary amines. It is known that lipophilicity is a key property that influences the ability of a drug to reach the target by transmembrane diffusion and to have a major effect on the biological activity [26]. Besides, augmented electron density may be another reason for better anticandidal activity due to the presence of electronically rich aromatic rings in Compounds 3a-3d. Thus, it may be suggested that increased lipophilic and/or electronic characters of Compounds 3a-3d caused an increase in anticandidal activity.

Table 1. $\mathrm{MIC}_{50}(\mu \mathrm{g} / \mathrm{mL})$ values of Compounds 3a-3o.

\begin{tabular}{ccccc}
\hline Comp. & C. albicans & C. glabrata & C. krusei & C. parapsilosis \\
\hline 3a & 3.125 & 3.125 & 0.78 & 0.78 \\
3b & 3.125 & 3.125 & 0.78 & 0.78 \\
3c & 1.56 & 0.78 & 0.78 & 0.78 \\
3d & 1.56 & 0.78 & 1.56 & 3.125 \\
3e & 50 & 12.50 & 12.50 & 12.50 \\
3f & 50 & 12.50 & 12.50 & 12.50 \\
3g & 50 & 12.50 & 25 & 12.50 \\
3h & 50 & 12.50 & 25 & 12.50 \\
3i & 50 & 12.50 & 12.50 & 12.50 \\
3j & 50 & 12.50 & 25 & 25 \\
3k & 50 & 25 & 25 & 12.50 \\
31 & 50 & 12.50 & 25 & 12.50 \\
3m & 50 & 12.50 & 12.50 & 25 \\
3n & 50 & 12.50 & 12.50 & 12.50 \\
3o & 50 & 12.50 & 12.50 & 12.50 \\
Ketoconazole & 0.78 & 1.56 & 1.56 & 1.56 \\
Fluconazole & 0.78 & 1.56 & 1.56 & 0.78 \\
\hline
\end{tabular}

\subsection{Quantification of the Ergosterol Level}

Sterols are neutral lipids of eukaryotic cells, among which ergosterol is the main constituent of fungal membranes. Ergosterol has biological functions such as membrane fluidity, regulation, activity and distribution of integral membrane proteins, and control of the cell cycle [27,28]. The critical role of sterols in maintenance of cell membranes make ergosterol and its biosynthetic pathway essential for fungal growth, and a primary target for antifungal drugs to treat fungal infections [6]. From this point of view, we performed an LCMSMS (Shimadzu LCMS 8040, Kyoto, Japan) method for quantitative determination of ergosterol content of C. krusei as reported in our recent study [29]. Compounds 3a-3d, displaying the best anticandidal activity and low cytotoxic effect, and reference agents ketoconazole and fluconazole were tested at concentrations of 0.78-3.12 $\mu \mathrm{g} / \mathrm{mL}$. Ergosterol standard (Product No.: 45480, Sigma-Aldrich, Darmstadt, Germany) was used for the quantification of ergostrerol in samples, which were treated with reference agents and Compounds 3a-3d. Ergosterol quantity of the negative control was considered as $100 \%$. Quadruplicate analyses were performed for all concentrations and the obtained data were expressed as mean \pm standard deviation (SD) (Table 2).

According to obtained results, the decrease in ergosterol level after administration of Compounds $\mathbf{3 a}-\mathbf{3 d}$ are noticeable when compared to the reference agents. Compounds $\mathbf{3 a - 3 \mathbf { d }}$ and reference 
agents significantly decreased the level of ergosterol at all tested concentrations. Therefore, it can be interpreted that Compounds $\mathbf{3 a} \mathbf{- 3} \mathbf{d}$ play a role in the ergosterol biosynthesis pathway.

\subsection{Cytotoxicity Test}

The main cause of failure in all stages of the new drug development process is toxicity. Early identification of toxicities of drug candidates is very important in terms of drug development studies [30]. Therefore, the MTT cell viability assay, which is suggested for cytotoxicity screening of drug candidates by ISO $(10993-5,2009)$ was performed [31]. Cytotoxicity of selected compounds (3a-3d), displaying strong anticandidal activity and good predicted pharmacokinetics, was determined against NIH/3T3 mouse embryonic fibroblast cell lines (ATCC CRL1658).

The cytotoxicity results of the tested compounds are presented in Table 2 . $\mathrm{IC}_{50}$ of compounds against NIH/3T3 was much higher than their MIC $_{50}$ values $(0.78-3.125 \mu \mathrm{g} / \mathrm{mL})$ against Candida strains. This finding shows that the antifungal activity of Compounds $\mathbf{3 a - 3 \mathbf { d }}$ is not due to general toxicity, but can be ascribed to their selective action against Candida species. Thus, cytotoxicity test findings enhanced the importance of Compounds $\mathbf{3 a}-\mathbf{3 d}$ as anticandidal drug candidates.

Table 2. Cytotoxic activity and ergosterol biosynthesis inhibition potency of Compounds 3a-3d against $\mathrm{NIH} / 3 \mathrm{~T} 3$ cell line and C. krusei, respectively.

\begin{tabular}{ccccc}
\hline \multirow{2}{*}{ Compound } & \multirow{2}{*}{$\mathbf{I C}_{\mathbf{5 0}}(\boldsymbol{\mu} \mathbf{g} / \mathbf{m L})$} & \multicolumn{3}{c}{ Inhibition of Ergosterol Biosynthesis $\mathbf{( \% )}$} \\
\cline { 3 - 5 } & & $\mathbf{0 . 7 8} \boldsymbol{\mu g} / \mathbf{m L}$ & $\mathbf{1 . 5 6} \boldsymbol{\mu g} / \mathbf{m L}$ & $\mathbf{3 . 1 2} \boldsymbol{\mu g} / \mathbf{m L}$ \\
\hline 3a & $>500$ & $66.19 \pm 2.23$ & $79.45 \pm 3.16$ & $86.47 \pm 4.77$ \\
3b & $>500$ & $68.59 \pm 1.98$ & $81.62 \pm 4.07$ & $83.49 \pm 3.18$ \\
3c & $436.04 \pm 1.03$ & $71.14 \pm 4.9$ & $78.16 \pm 2.70$ & $84.28 \pm 4.65$ \\
3d & $387.64 \pm 20.20$ & $52.47 \pm 1.83$ & $67.14 \pm 2.70$ & $74.14 \pm 2.21$ \\
Ketoconazole & - & $60.99 \pm 2.94$ & $73.12 \pm 4.16$ & $84.56 \pm 3.01$ \\
Fluconazole & - & $61.74 \pm 1.70$ & $70.12 \pm 3.22$ & $82.13 \pm 4.45$ \\
\hline
\end{tabular}

\subsection{Molecular Docking Studies}

Docking studies were performed in order to gain more insight into the binding mode of the most active compound $3 c$ to lanosterol 14- $\alpha$-demethylase. Lanosterol 14- $\alpha$-demethylase from Mycobacterium tuberculosis has high homology compared with lanosterol 14- $\alpha$-demethylase from Candida species. It has been reported that these two enzymes have a high degree of similarity between the hydrophobic cavities of the catalytic site [29,32]. Therefore, docking studies were carried out using X-ray crystal structure of lanosterol 14- $\alpha$-demethylase from Mycobacterium tuberculosis in complex with fluconazole (PDB ID: 1EA1) [33] obtained from the Protein Data Bank server (www.pdb.org).

As stated in the antifungal activity section, Compound $3 \mathrm{c}$ was found to be the most active derivative against C. albicans, C. glabrata, C. krusei, and C. parapsilosis with 1.56, 0.78, 0.78, and $0.78 \mu \mathrm{g} / \mathrm{mL}$ MIC values, respectively. Thus, the main purpose of docking studies was to investigate the possible interaction of this compound with lanosterol 14- $\alpha$-demethylase enzyme.

The docking pose on lanesterol 14- $\alpha$-sterol demethylase reveals that the interactions between Compound 3c and HEM450 are very important in terms of binding to the active site of the enzyme (Figure 2). Imidazole and its neighboring phenyl established two $\pi-\pi$ interactions. The other two $\pi-\pi$ interactions were formed by other phenyl rings of the structure. Phenyl of benzylidene was in interaction with Arg96, while phenyl substituted with methoxy group created a $\pi-\pi$ interaction with the phenyl of Phe78. Additionally, the docking pose showed that there were three hydrogen bonds providing polar interactions. Carbonyl of Compound 3c established a hydrogen bond with the amino of Val395. Oxygen atoms of phenoxy created this interaction with the amino of Met79, whereas oxygen atoms of the methoxy group formed with the amino of Ile323. These interactions explain the stronger anticandidal activity of 3c. It could be that C-4 of phenyl is very important in terms of binding to the 
enzyme active site and anticandidal activity. As a result, this additional interaction could explain the greater binding capability and stronger activity of Compound 3c compared with other compounds.

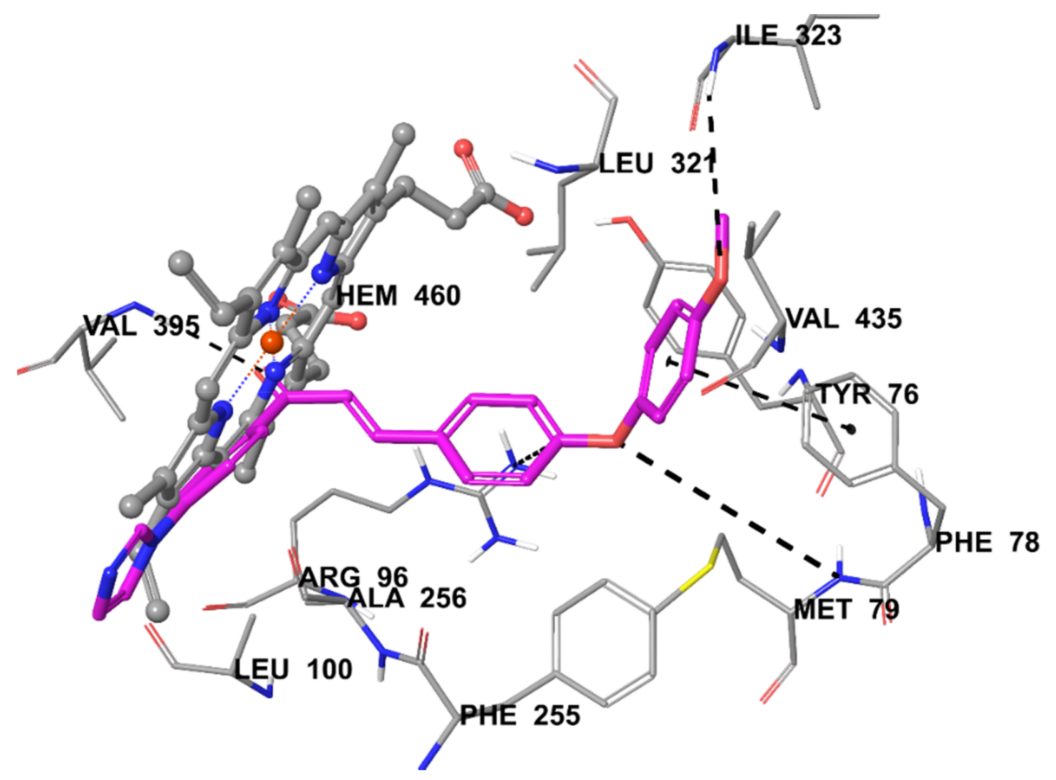

Figure 2. The interacting mode of Compound 3c in the active region of 14-alpha-sterol demethylase. The inhibitor is colored with purple and HEM with grey.

\section{Materials and Methods}

\subsection{Chemistry}

All chemicals used in the syntheses were purchased either from Sigma-Aldrich Chemicals (Sigma-Aldrich Corp., St. Louis, MO, USA) or Merck Chemicals (Merck KGaA, Darmstadt, Germany). Melting points of the synthesized compounds were measured by MP90 digital melting point apparatus (Mettler Toledo, Columbus, OH, USA) and were presented as uncorrected. ${ }^{1} \mathrm{H}-\mathrm{NMR}$ and ${ }^{13} \mathrm{C}-\mathrm{NMR}$ spectra were recorded by a Bruker $300 \mathrm{MHz}$ and $75 \mathrm{MHz}$ digital FT-NMR spectrometer (Bruker Bioscience, Billerica, MA, USA) in DMSO- $d_{6}$, respectively. In the NMR spectra, splitting patterns were designated as follows: s: singlet; d: doublet; t: triplet; m: multiplet. Coupling constants $(J)$ were reported as Hertz. The IR spectra of the compounds were recorded using an IRAffinity-1S Fourier transform IR (FTIR) spectrometer (Shimadzu, Tokyo, Japan). LC-MS-MS studies were performed on a Schimadzu, 8040 LCMSMS spectrophotometer (Shimadzu, Tokyo, Japan). The purities of compounds were checked by TLC on silica gel 60 F254 (Merck KGaA, Darmstadt, Germany).

\subsubsection{Synthesis of $4^{\prime}$-(Imidazol-1-yl)acetophenone (1)}

4-Fluoro acetofenone (4.976 mL, $0.041 \mathrm{~mol})$, imidazole ( $2.789 \mathrm{~g}, 0.041 \mathrm{~mol})$, and sodium hydride $(\mathrm{NaH})(1.080 \mathrm{~g}, 0.045 \mathrm{~mol})$ in DMF were refluxed for $12 \mathrm{~h}$. After cooling, the mixture was poured into the ice water, and the precipitated product was washed with water, dried, and recrystallized from ethanol.

\subsubsection{Synthesis of Four Substituted Benzaldehydes (2a-2o)}

A mixture of 4-fluoro benzaldehyde $(0.259 \mathrm{~mL}, 0.002 \mathrm{~mol})$, corresponding phenol, thiophenol, or amine $(0.002 \mathrm{~mol})$, and a catalytic quantity of potassium carbonate $\left(\mathrm{K}_{2} \mathrm{CO}_{3}\right)$ was refluxed in DMF $(20 \mathrm{~mL})$ for $36 \mathrm{~h}$. After completion of the reaction, the mixture was poured into ice water $(50 \mathrm{~mL})$, and the precipitated product was filtered, washed with deionized water, dried, and recrystallized from ethanol. 


\subsubsection{General Procedure for the Synthesis of Target Compounds (3a-3o)}

1-(4-(1H-imidazol-1-yl)phenyl)ethan-1-one (1) $(0.316 \mathrm{~g}, 0.0017 \mathrm{~mol})$ and appropriate 4-substituted benzaldehydes $(\mathbf{2 a}-\mathbf{2 o})$ derivatives $(0.0017 \mathrm{~mol})$ in methanol were stirred for $10 \mathrm{~h}$ in the presence of potassium hydroxide. The precipitated product was washed with water, dried, and recrystallized from ethanol.

1-(4-(1H-Imidazol-1-yl)phenyl)-3-(4-(p-tolyloxy)phenyl)prop-2-en-1-one (3a): Yield: 79\%, M.P. $=146-148{ }^{\circ} \mathrm{C}$, FTIR (ATR, cm $\left.{ }^{-1}\right): 3128(\mathrm{C}-\mathrm{H}), 1653(\mathrm{C}=\mathrm{O}), 1373(\mathrm{C}=\mathrm{N}), 814 .{ }^{1} \mathrm{H}-\mathrm{NMR}\left(300 \mathrm{MHz}, \mathrm{DMSO}-d_{6}\right): 2.32(3 \mathrm{H}$, $\left.\mathrm{s}, \mathrm{CH}_{3}\right), 7.01(2 \mathrm{H}, \mathrm{d}, J=8.5 \mathrm{~Hz}$, disubstituted $\mathrm{CH}), 7.02(2 \mathrm{H}, \mathrm{d}, J=8.8 \mathrm{~Hz}$, disubstituted $\mathrm{CH}), 7.17(1 \mathrm{H}, \mathrm{s}$, imidazole CH), $7.25(2 \mathrm{H}, \mathrm{d}, J=8.2 \mathrm{~Hz}$, methylphenyl $\mathrm{CH}), 7.76(1 \mathrm{H}, \mathrm{d}, J=15.6 \mathrm{~Hz},-\mathrm{HC}=\mathrm{CH}-), 7.87-7.94$ $(6 \mathrm{H}, \mathrm{m}$, disubstituted $\mathrm{CH}$, methylphenyl $\mathrm{CH}$, imidazole $\mathrm{CH},-\mathrm{HC}=\mathrm{CH}-), 8.00(1 \mathrm{H}, \mathrm{d}, J=15.6 \mathrm{~Hz}$, $-\mathrm{HC}=\mathrm{CH}-), 8.30(2 \mathrm{H}, \mathrm{d}, J=8.8 \mathrm{~Hz}$, disubstituted $\mathrm{CH}), 8.47(1 \mathrm{H}$, s, imidazole $\mathrm{CH}) .{ }^{13} \mathrm{C}-\mathrm{NMR}(75 \mathrm{MHz}$, DMSO- $\left.d_{6}\right): \delta=20.8,118.2,118.3,120.1,120.3,121.0,129.8,130.9,131.1,131.5,134.0,136.1,136.2,140.7$, 144.1, 153.6, 160.1, 188.2. ESI-MS [M + H] $]^{+}: 381.25(100 \%)$.

1-(4-(1H-Imidazol-1-yl)phenyl)-3-(4-(p-tolylthio)phenyl)prop-2-en-1-one (3b): Yield: 84\%, M.P. = 168-169 ${ }^{\circ} \mathrm{C}$, FTIR (ATR, $\left.\mathrm{cm}^{-1}\right)$ : $3120(\mathrm{C}-\mathrm{H}), 1651(\mathrm{C}=\mathrm{O}), 1337(\mathrm{C}=\mathrm{N}), 812 .{ }^{1} \mathrm{H}-\mathrm{NMR}\left(300 \mathrm{MHz}, \mathrm{DMSO}-d_{6}\right): 2.35(3 \mathrm{H}$, $\left.\mathrm{s}, \mathrm{CH}_{3}\right), 7.17(1 \mathrm{H}, \mathrm{t}, J=1.1 \mathrm{~Hz}$, imidazole $\mathrm{CH}), 7.21(2 \mathrm{H}, \mathrm{d}, J=8.3 \mathrm{~Hz}$, disubstituted $\mathrm{CH}), 7.29(2 \mathrm{H}$, $\mathrm{d}, J=7.9 \mathrm{~Hz}$, methylphenyl CH), $7.40(2 \mathrm{H}, \mathrm{d}, J=8.3 \mathrm{~Hz}$, disubstituted $\mathrm{CH}), 7.72(1 \mathrm{H}, \mathrm{d}, J=15.6 \mathrm{~Hz}$, $-\mathrm{HC}=\mathrm{CH}-), 7.84-7.88(3 \mathrm{H}, \mathrm{m}$, methylphenyl $\mathrm{CH}$, imidazole $\mathrm{CH}), 7.89-7.98(3 \mathrm{H}, \mathrm{m}$, disubstituted $\mathrm{CH}$, $-\mathrm{HC}=\mathrm{CH}-), 8.00(1 \mathrm{H}, \mathrm{d}, J=15.6 \mathrm{~Hz},-\mathrm{HC}=\mathrm{CH}-), 8.29(2 \mathrm{H}, \mathrm{d}, J=8.8 \mathrm{~Hz}$, disubstituted $\mathrm{CH}), 8.47(1 \mathrm{H}, \mathrm{s}$, imidazole CH). ${ }^{13} \mathrm{C}-\mathrm{NMR}\left(75 \mathrm{MHz}, \mathrm{DMSO}-d_{6}\right): \delta=21.2,118.3,120.3,122.0,128.4,128.9,130.3,130.9$, $130.9,131.0,132.9,133.8,135.9,136.2,139.1,140.7,141.1,143.9,188.2$. ESI-MS [M + H] $]^{+} 397.20$ (100\%).

1-(4-(1H-Imidazol-1-yl)phenyl)-3-(4-(4-methoxyphenoxy)phenyl)prop-2-en-1-one (3c): Yield: 92\%, M.P. = 168-170 ${ }^{\circ} \mathrm{C}$, FTIR (ATR, $\left.\mathrm{cm}^{-1}\right)$ : $3144(\mathrm{C}-\mathrm{H}), 1653(\mathrm{C}=\mathrm{O}), 1342(\mathrm{C}=\mathrm{N}), 814 .{ }^{1} \mathrm{H}-\mathrm{NMR}(300 \mathrm{MHz}$, DMSO-d $\left.)_{6}\right): 3.78\left(3 \mathrm{H}, \mathrm{s}, \mathrm{OCH}_{3}\right), 6.98(2 \mathrm{H}, \mathrm{d}, J=8.8 \mathrm{~Hz}$, methoxyphenyl CH), $7.01(2 \mathrm{H}, \mathrm{d}, J=9.2 \mathrm{~Hz}$, disubstituted $\mathrm{CH}), 7.09(2 \mathrm{H}, \mathrm{d}, J=9.2 \mathrm{~Hz}$, disubstituted $\mathrm{CH}), 7.17(1 \mathrm{H}, \mathrm{t}, J=1.1 \mathrm{~Hz}$, imidazole $\mathrm{CH}), 7.75$ $(1 \mathrm{H}, \mathrm{d}, J=15.5 \mathrm{~Hz},-\mathrm{HC}=\mathrm{CH}-), 7.87-7.93(6 \mathrm{H}, \mathrm{m}$, methoxyphenyl $\mathrm{CH}$, disubstituted $\mathrm{CH}$, imidazole $\mathrm{CH}$, $-\mathrm{HC}=\mathrm{CH}-), 8.29(2 \mathrm{H}, \mathrm{d}, J=8.8 \mathrm{~Hz}$, disubstituted $\mathrm{CH}), 8.47(1 \mathrm{H}, \mathrm{t}, J=1.1 \mathrm{~Hz}$, imidazole $\mathrm{CH}) .{ }^{13} \mathrm{C}-\mathrm{NMR}$ $\left(75 \mathrm{MHz}, \mathrm{DMSO}-d_{6}\right): \delta=55.9,115.7,117.5,118.3,120.3,120.8,121.8,129.5,130.9,131.3,131.5,136.1$, 136.2, 140.6, 144.2, 148.9, 156.6, 160.8, 188.2. ESI-MS [M+ H] $]^{+}: 397.25(100 \%)$.

1-(4-(1H-Imidazol-1-yl)phenyl)-3-(4-((4-methoxyphenyl)thio)phenyl)prop-2-en-1-one (3d): Yield: 80\%, M.P. $=177-179{ }^{\circ} \mathrm{C}$, FTIR $\left(\mathrm{ATR}, \mathrm{cm}^{-1}\right): 3111(\mathrm{C}-\mathrm{H}), 1657(\mathrm{C}=\mathrm{O}), 1369(\mathrm{C}=\mathrm{N}), 808 .{ }^{1} \mathrm{H}-\mathrm{NMR}(300 \mathrm{MHz}$, DMSO-d $\left.)_{6}\right): 3.81\left(3 \mathrm{H}, \mathrm{s}, \mathrm{OCH}_{3}\right), 7.06(2 \mathrm{H}, \mathrm{d}, J=8.8 \mathrm{~Hz}$, methoxyphenyl $\mathrm{CH}), 7.12(2 \mathrm{H}, \mathrm{d}, J=8.4 \mathrm{~Hz}$, disubstituted $\mathrm{CH}), 7.17(1 \mathrm{H}, \mathrm{s}$, imidazole $\mathrm{CH}), 7.49(2 \mathrm{H}, \mathrm{d}, J=8.8 \mathrm{~Hz}$, methoxyphenyl $\mathrm{CH}), 7.70(1 \mathrm{H}, \mathrm{d}$, $J=15.6 \mathrm{~Hz},-\mathrm{HC}=\mathrm{CH}-), 7.81(2 \mathrm{H}, \mathrm{d}, J=8.4 \mathrm{~Hz}$, disubstituted $\mathrm{CH}), 7.87(2 \mathrm{H}, \mathrm{d}, J=8.8 \mathrm{~Hz}$, disubstituted $\mathrm{CH}), 7.91(1 \mathrm{H}, \mathrm{t}, J=1.4 \mathrm{~Hz}$, imidazole $\mathrm{CH}), 7.92(1 \mathrm{H}, \mathrm{d}, J=15.6 \mathrm{~Hz},-\mathrm{HC}=\mathrm{CH}-), 8.27(2 \mathrm{H}, \mathrm{d}, J=8.8 \mathrm{~Hz}$, disubstituted $\mathrm{CH}), 8.46(1 \mathrm{H}, \mathrm{s}$, imidazole $\mathrm{CH}) .{ }^{13} \mathrm{C}-\mathrm{NMR}\left(75 \mathrm{MHz}, \mathrm{DMSO}-d_{6}\right): \delta=55.9,116.1,118.3$, $120.3,121.7,121.8,127.2,130.2,130.9,132.5,136.0,136.2,136.6,140.7,142.6,143.9,160.7,188.2$. ESI-MS $[\mathrm{M}+\mathrm{H}]^{+}: 413.20(100 \%)$.

1-(4-(1H-Imidazol-1-yl)phenyl)-3-(4-(pyrrolidin-1-yl)phenyl)prop-2-en-1-one (3e): Yield: 77\%, M.P. = 186-188 ${ }^{\circ} \mathrm{C}$, FTIR (ATR, cm $\left.{ }^{-1}\right): 3109(\mathrm{C}-\mathrm{H}), 1655(\mathrm{C}=\mathrm{O}), 1373(\mathrm{C}=\mathrm{N}), 810 .{ }^{1} \mathrm{H}-\mathrm{NMR}\left(300 \mathrm{MHz}, \mathrm{DMSO}-d_{6}\right): \delta$ 1.94-1.98 (4H, m, pyrrolidine $\left.\mathrm{CH}_{2}\right), 3.28-3.32\left(4 \mathrm{H}, \mathrm{m}\right.$, pyrrolidine $\left.\mathrm{CH}_{2}\right), 6.58(2 \mathrm{H}, \mathrm{d}, J=8.8 \mathrm{~Hz}$, disubstituted $\mathrm{CH}), 7.16(1 \mathrm{H}, \mathrm{s}$, imidazole $\mathrm{CH}), 7.63-7.73(4 \mathrm{H}, \mathrm{m}$, disubstituted $\mathrm{CH},-\mathrm{HC}=\mathrm{CH}-), 7.85$ $(2 \mathrm{H}, \mathrm{d}, J=8.7 \mathrm{~Hz}$, disubstituted $\mathrm{CH}), 7.90(1 \mathrm{H}, \mathrm{t}, J=1.2 \mathrm{~Hz}$, imidazole $\mathrm{CH}), 8.25(2 \mathrm{H}, \mathrm{d}, J=8.7 \mathrm{~Hz}$, disubstituted $\mathrm{CH}), 8.44(1 \mathrm{H}, \mathrm{s}$, imidazole $\mathrm{CH}) .{ }^{13} \mathrm{C}-\mathrm{NMR}\left(75 \mathrm{MHz}\right.$, DMSO- $\left.d_{6}\right): \delta=25.4,47.8,112.2$, $115.6,118.3,120.2,121.9,130.5,130.8,131.6,136.2,136.9,140.2,146.2,149.9,187.6$. ESI-MS [M + H] ${ }^{+}$: $344.25(100 \%)$. 
1-(4-(1H-Imidazol-1-yl)phenyl)-3-(4-morpholinophenyl)prop-2-en-1-one (3f): Yield: 79\%, M.P. $=214-215{ }^{\circ} \mathrm{C}$, FTIR (ATR, cm ${ }^{-1}$ ): $3109(\mathrm{C}-\mathrm{H}), 1653(\mathrm{C}=\mathrm{O}), 1337(\mathrm{C}=\mathrm{N}), 812 .{ }^{1} \mathrm{H}-\mathrm{NMR}\left(300 \mathrm{MHz}, \mathrm{DMSO}-d_{6}\right): \delta 3.27$ $\left(4 \mathrm{H}, \mathrm{t}, J=4.9 \mathrm{~Hz}\right.$, morpholine $\left.\mathrm{CH}_{2}\right), 3.75\left(4 \mathrm{H}, \mathrm{t}, J=4.9 \mathrm{~Hz}\right.$, morpholine $\left.\mathrm{CH}_{2}\right), 7.00(2 \mathrm{H}, \mathrm{d}, J=8.8 \mathrm{~Hz}$, disubstituted $\mathrm{CH}), 7.16(1 \mathrm{H}, \mathrm{t}, J=1.0 \mathrm{~Hz}$, imidazole $\mathrm{CH}), 7.71(2 \mathrm{H}, \mathrm{d}, J=15.4 \mathrm{~Hz},-\mathrm{HC}=\mathrm{CH}-), 7.74-7.82$ $(3 \mathrm{H}, \mathrm{m}$, disubstituted $\mathrm{CH},-\mathrm{HC}=\mathrm{CH}-), 7.86(2 \mathrm{H}, \mathrm{d}, J=8.8 \mathrm{~Hz}$, disubstituted $\mathrm{CH}), 7.90(1 \mathrm{H}, \mathrm{t}, J=1.2 \mathrm{~Hz}$, imidazole $\mathrm{CH}), 8.25(2 \mathrm{H}, \mathrm{d}, J=8.7 \mathrm{~Hz}$, disubstituted $\mathrm{CH}), 8.44(1 \mathrm{H}$, s, imidazole $\mathrm{CH}) .{ }^{13} \mathrm{C}-\mathrm{NMR}$ $\left(75 \mathrm{MHz}, \mathrm{DMSO}-d_{6}\right): \delta=47.6,63.4,114.6,117.9,118.3,120.2,125.2,130.7,130.8,131.1,136.2,136.6$, 140.4, 145.3, 153.2, 187.9. ESI-MS [M + H] $]^{+}: 360.25(100 \%)$.

1-(4-(1H-Imidazol-1-yl)phenyl)-3-(4-(piperidin-1-yl)phenyl)prop-2-en-1-one (3g): Y Yield: 73\%, M.P. $=198-199{ }^{\circ} \mathrm{C}$, FTIR (ATR, $\mathrm{cm}^{-1}$ ): $3078(\mathrm{C}-\mathrm{H}), 1657(\mathrm{C}=\mathrm{O}), 1389(\mathrm{C}=\mathrm{N}), 812 .{ }^{1} \mathrm{H}-\mathrm{NMR}\left(300 \mathrm{MHz}, \mathrm{DMSO}-d_{6}\right): \delta 1.58$ $\left(6 \mathrm{H}\right.$, s, piperidine $\left.\mathrm{CH}_{2}\right), 3.32\left(4 \mathrm{H}\right.$, s, piperidine $\left.\mathrm{CH}_{2}\right), 6.95(2 \mathrm{H}, \mathrm{d}, J=8.9 \mathrm{~Hz}$, disubstituted $\mathrm{CH}), 7.16$ $(1 \mathrm{H}, \mathrm{t}, J=1.0 \mathrm{~Hz}$, imidazole $\mathrm{CH}), 7.71-7.82(4 \mathrm{H}, \mathrm{m}$, disubstituted $\mathrm{CH},-\mathrm{HC}=\mathrm{CH}-), 7.86(2 \mathrm{H}, \mathrm{d}, J=8.7 \mathrm{~Hz}$, disubstituted $\mathrm{CH}), 7.91(1 \mathrm{H}, \mathrm{t}, J=1.3 \mathrm{~Hz}$, imidazole $\mathrm{CH}), 8.26(2 \mathrm{H}, \mathrm{d}, J=8.7 \mathrm{~Hz}$, disubstituted $\mathrm{CH})$, $8.45\left(1 \mathrm{H}\right.$, s, imidazole CH). ${ }^{13} \mathrm{C}-\mathrm{NMR}\left(75 \mathrm{MHz}\right.$, DMSO- $\left.d_{6}\right): \delta=24.4,25.4,48.5,114.6,117.2,118.3,120.2$, $123.9,130.7,130.8,131.3,136.2,136.7,140.3,145.5,153.2,187.8$. ESI-MS $[M+2 H]^{2+}: 179.70(100 \%)$.

1-(4-(1H-Imidazol-1-yl)phenyl)-3-(4-(3-methylpiperidin-1-yl)phenyl)prop-2-en-1-one (3h): Yield: 80\%, M.P. $=163-165^{\circ} \mathrm{C}$, FTIR (ATR, cm $\left.{ }^{-1}\right): 3107(\mathrm{C}-\mathrm{H}), 1655(\mathrm{C}=\mathrm{O}), 1339(\mathrm{C}=\mathrm{N}), 812 .{ }^{1} \mathrm{H}-\mathrm{NMR}(300 \mathrm{MHz}$, DMSO- $\left.d_{6}\right): 0.92\left(3 \mathrm{H}, \mathrm{d}, J=6.6 \mathrm{~Hz}, \mathrm{CH}_{3}\right), 1.04-1.17(1 \mathrm{H}, \mathrm{m}$, piperidine $\mathrm{CH}), 1.43-1.80(5 \mathrm{H}, \mathrm{m}$, piperidine $\left.\mathrm{CH}_{2}\right), 2.73-2.82\left(1 \mathrm{H}, \mathrm{m}\right.$, piperidine $\left.\mathrm{CH}_{2}\right), 3.77-3.85\left(2 \mathrm{H}, \mathrm{m}\right.$, piperidine $\left.\mathrm{CH}_{2}\right), 6.96(2 \mathrm{H}, \mathrm{d}, J=9.0 \mathrm{~Hz}$, disubstituted $\mathrm{CH}), 7.16(1 \mathrm{H}, \mathrm{s}$, imidazole $\mathrm{CH}), 7.71-7.73(4 \mathrm{H}, \mathrm{m}$, disubstituted $\mathrm{CH},-\mathrm{HC}=\mathrm{CH}-), 7.86$ $(2 \mathrm{H}, \mathrm{d}, J=8.8 \mathrm{~Hz}$, disubstituted $\mathrm{CH}), 7.91(1 \mathrm{H}, \mathrm{t}, J=1.2 \mathrm{~Hz}$, imidazole $\mathrm{CH}), 8.26(2 \mathrm{H}, \mathrm{d}, J=8.8 \mathrm{~Hz}$, disubstituted $\mathrm{CH}), 8.45(1 \mathrm{H}$, s, imidazole $\mathrm{CH}) .{ }^{13} \mathrm{C}-\mathrm{NMR}\left(75 \mathrm{MHz}\right.$, DMSO- $\left.d_{6}\right): \delta=19.6,24.8,30.6,33.0$, 47.9, 55.3, 114.6, 117.1, 118.3, 120.2, 123.8, 130.6, 130.8, 131.4, 136.2, 136.7, 140.3, 145.5, 152.9, 187.8 . ESI-MS $[\mathrm{M}+2 \mathrm{H}]^{2+}: 186.70(100 \%)$.

1-(4-(1H-Imidazol-1-yl)phenyl)-3-(4-(4-methylpiperidin-1-yl)phenyl)prop-2-en-1-one (3i): Yield: 77\%, M.P. $=189-191^{\circ} \mathrm{C}$, FTIR (ATR, cm $\left.{ }^{-1}\right): 3117(\mathrm{C}-\mathrm{H}), 1657(\mathrm{C}=\mathrm{O}), 1339(\mathrm{C}=\mathrm{N}), 812 .{ }^{1} \mathrm{H}-\mathrm{NMR}(300 \mathrm{MHz}$, DMSO- $\left.d_{6}\right): \delta 0.92\left(3 \mathrm{H}, \mathrm{d}, J=6.4 \mathrm{~Hz}, \mathrm{CH}_{3}\right), 1.10-1.24\left(2 \mathrm{H}, \mathrm{m}\right.$, piperidine $\left.\mathrm{CH}_{2}\right), 1.52-1.70(3 \mathrm{H}, \mathrm{m}$, piperidine $\left.\mathrm{CH}_{2}\right), 2.76-2.85\left(2 \mathrm{H}, \mathrm{m}\right.$, piperidine $\left.\mathrm{CH}_{2}\right), 3.87-3.91\left(2 \mathrm{H}, \mathrm{m}\right.$, piperidine $\left.\mathrm{CH}_{2}\right), 6.96(2 \mathrm{H}, \mathrm{d}$, $J=8.9 \mathrm{~Hz}$, disubstituted $\mathrm{CH}), 7.16(1 \mathrm{H}, \mathrm{t}, J=1.0 \mathrm{~Hz}$, imidazole $\mathrm{CH}), 7.71-7.74(4 \mathrm{H}, \mathrm{m}$, disubstituted $\mathrm{CH}$, $-\mathrm{HC}=\mathrm{CH}-), 7.86(2 \mathrm{H}, \mathrm{d}, J=8.7 \mathrm{~Hz}$, disubstituted $\mathrm{CH}), 7.91(1 \mathrm{H}, \mathrm{t}, J=1.3 \mathrm{~Hz}$, imidazole $\mathrm{CH}), 8.26(2 \mathrm{H}$, $\mathrm{d}, J=8.7 \mathrm{~Hz}$, disubstituted $\mathrm{CH}), 8.45(1 \mathrm{H}, \mathrm{s}$, imidazole $\mathrm{CH}) .{ }^{13} \mathrm{C}-\mathrm{NMR}\left(75 \mathrm{MHz}\right.$, DMSO- $\left.d_{6}\right): \delta=22.2$, 30.8, 33.6, 47.9, 114.7, 117.2, 118.3, 120.2, 123.9, 130.7, 130.8, 131.3, 136.2, 136.7, 140.3, 145.5, 153.0, 187.8. ESI-MS $[\mathrm{M}+2 \mathrm{H}]^{2+}: 186.75(100 \%)$.

1-(4-(1H-Imidazol-1-yl)phenyl)-3-(4-(3,5-dimethylpiperidin-1-yl)phenyl)prop-2-en-1-one (3j): Yield: 81\%, M.P. $=160-161{ }^{\circ} \mathrm{C}$, FTIR (ATR, cm $\left.{ }^{-1}\right): 3035(\mathrm{C}-\mathrm{H}), 1622(\mathrm{C}=\mathrm{O}), 1335(\mathrm{C}=\mathrm{N}), 815 .{ }^{1} \mathrm{H}-\mathrm{NMR}(300 \mathrm{MHz}$, DMSO- $\left.d_{6}\right): \delta 0.90\left(6 \mathrm{H}, \mathrm{d}, J=6.5 \mathrm{~Hz}, \mathrm{CH}_{3}\right), 1.59-1.79\left(4 \mathrm{H}, \mathrm{m}\right.$, piperidine $\left.\mathrm{CH}_{2}\right), 2.28-2.36(2 \mathrm{H}, \mathrm{m}$, piperidine $\left.\mathrm{CH}_{2}\right), 3.85-3.90\left(2 \mathrm{H}, \mathrm{m}\right.$, piperidine $\left.\mathrm{CH}_{2}\right), 6.97(2 \mathrm{H}, \mathrm{d}, J=9.0 \mathrm{~Hz}$, disubstituted $\mathrm{CH}), 7.16(1 \mathrm{H}$, $\mathrm{t}, J=1.0 \mathrm{~Hz}$, imidazole $\mathrm{CH}), 7.70-7.73(4 \mathrm{H}, \mathrm{m}$, disubstituted $\mathrm{CH},-\mathrm{HC}=\mathrm{CH}-), 7.86(2 \mathrm{H}, \mathrm{d}, J=8.8 \mathrm{~Hz}$, disubstituted $\mathrm{CH}), 7.91(1 \mathrm{H}, \mathrm{t}, J=1.3 \mathrm{~Hz}$, imidazole $\mathrm{CH}), 8.23(2 \mathrm{H}, \mathrm{d}, J=8.8 \mathrm{~Hz}$, disubstituted $\mathrm{CH}), 8.45$ $(1 \mathrm{H}$, s, imidazole $\mathrm{CH}) .{ }^{13} \mathrm{C}-\mathrm{NMR}\left(75 \mathrm{MHz}\right.$, DMSO- $\left.d_{6}\right): \delta=19.5,30.5,42.4,54.8,114.5,117.1,118.3,120.2$, $123.7,130.6,130.8,131.4,136.2,136.7,140.3,145.5,152.7,187.9$. ESI-MS $[M+2 H]^{2+}: 193.70(100 \%)$.

1-(4-(1H-Imidazol-1-yl)phenyl)-3-(4-(4-benzylpiperidin-1-yl)phenyl)prop-2-en-1-one (3k): Yield: 83\%, M.P. $=178-180^{\circ} \mathrm{C}$, FTIR (ATR, cm $\left.{ }^{-1}\right): 3062(\mathrm{C}-\mathrm{H}), 1601(\mathrm{C}=\mathrm{O}), 1296(\mathrm{C}=\mathrm{N}), 814 .{ }^{1} \mathrm{H}-\mathrm{NMR}(300 \mathrm{MHz}$, DMSO- $\left.d_{6}\right): \delta 1.17-1.31\left(2 \mathrm{H}, \mathrm{m}\right.$, piperidine $\left.\mathrm{CH}_{2}\right), 1.63-1.77\left(3 \mathrm{H}, \mathrm{m}\right.$, piperidine $\left.\mathrm{CH}_{2}\right), 2.54(2 \mathrm{H}, \mathrm{d}$, $\left.J=7.1 \mathrm{~Hz}, \mathrm{CH}_{2}\right), 2.73-2.81\left(2 \mathrm{H}, \mathrm{m}\right.$, piperidine $\left.\mathrm{CH}_{2}\right), 3.88-3.92\left(2 \mathrm{H}, \mathrm{m}\right.$, piperidine $\left.\mathrm{CH}_{2}\right), 6.96(2 \mathrm{H}$, $\mathrm{d}, J=9.0 \mathrm{~Hz}$, disubstituted $\mathrm{CH}), 7.16-7.21(4 \mathrm{H}, \mathrm{m}$, monosubstituted benzene $\mathrm{CH}$, imidazole $\mathrm{CH})$, 7.27-7.29 $(2 \mathrm{H}, \mathrm{m}$, monosubstituted benzene $\mathrm{CH}), 7.71-7.74(4 \mathrm{H}, \mathrm{m}$, disubstituted $\mathrm{CH},-\mathrm{HC}=\mathrm{CH}-), 7.86$ $(2 \mathrm{H}, \mathrm{d}, J=8.8 \mathrm{~Hz}$, disubstituted $\mathrm{CH}), 7.91(1 \mathrm{H}, \mathrm{t}, J=1.4 \mathrm{~Hz}$, imidazole $\mathrm{CH}), 8.26(2 \mathrm{H}, \mathrm{d}, J=8.8 \mathrm{~Hz}$, 
disubstituted $\mathrm{CH}), 8.45(1 \mathrm{H}, \mathrm{t}, J=1.0 \mathrm{~Hz}$, imidazole $\mathrm{CH}) .{ }^{13} \mathrm{C}-\mathrm{NMR}\left(75 \mathrm{MHz}, \mathrm{DMSO}-d_{6}\right): \delta=31.5,37.8$, 42.7, 47.8, 114.7, 117.2, 118.3, 120.2, 123.9, 126.3, 128.6, 129.5, 130.7, 130.8, 131.3, 136.2, 136.7, 140.3, 140.6, $145.5,152.9,187.9$. ESI-MS $[\mathrm{M}+2 \mathrm{H}]^{2+}: 224.75(100 \%)$.

1-(4-(1H-Imidazol-1-yl)phenyl)-3-(4-(4-methylpiperazin-1-yl)phenyl)prop-2-en-1-one (31): Yield: 82\%, M.P. $=205-207^{\circ} \mathrm{C}$, FTIR $\left(A T R, \mathrm{~cm}^{-1}\right): 3109(\mathrm{C}-\mathrm{H}), 1655(\mathrm{C}=\mathrm{O}), 1337(\mathrm{C}=\mathrm{N}), 812 .{ }^{1} \mathrm{H}-\mathrm{NMR}(300 \mathrm{MHz}$, DMSO- $\left.d_{6}\right): \delta 2.22\left(3 \mathrm{H}, \mathrm{s}, \mathrm{CH}_{3}\right), 2.43\left(4 \mathrm{H}, \mathrm{t}, J=5.0 \mathrm{~Hz}\right.$, piperazine $\left.\mathrm{CH}_{2}\right), 3.30(4 \mathrm{H}, \mathrm{t}, J=5.0 \mathrm{~Hz}$, piperazine $\left.\mathrm{CH}_{2}\right), 6.98(2 \mathrm{H}, \mathrm{d}, J=8.9 \mathrm{~Hz}$, disubstituted $\mathrm{CH}), 7.16(1 \mathrm{H}, \mathrm{t}, J=1.2 \mathrm{~Hz}$, imidazole $\mathrm{CH}), 7.72-7.76(4 \mathrm{H}$, $\mathrm{m}$, disubstituted $\mathrm{CH},-\mathrm{HC}=\mathrm{CH}-), 7.86(2 \mathrm{H}, \mathrm{d}, J=8.8 \mathrm{~Hz}$, disubstituted $\mathrm{CH}), 7.91(1 \mathrm{H}, \mathrm{t}, J=1.3 \mathrm{~Hz}$, imidazole $\mathrm{CH}), 8.27(2 \mathrm{H}, \mathrm{d}, J=8.8 \mathrm{~Hz}$, disubstituted $\mathrm{CH}), 8.45(1 \mathrm{H}$, s, imidazole $\mathrm{CH}) .{ }^{13} \mathrm{C}-\mathrm{NMR}$ $\left(75 \mathrm{MHz}, \mathrm{DMSO}-d_{6}\right): \delta=46.2,47.3,54.8,114.7,117.7,118.3,120.2,124.7,130.7,130.8,131.2,136.2,136.6$, $140.4,145.3,153.0,187.9$. ESI-MS $[\mathrm{M}+2 \mathrm{H}]^{2+}: 187.20(100 \%)$.

1-(4-(1H-Imidazol-1-yl)phenyl)-3-(4-(4-ethylpiperazin-1-yl)phenyl)prop-2-en-1-one (3m): Yield: 86\%, M.P. $=188-189^{\circ} \mathrm{C}$, FTIR $\left(\mathrm{ATR}, \mathrm{cm}^{-1}\right): 3125(\mathrm{C}-\mathrm{H}), 1653(\mathrm{C}=\mathrm{O}), 1337(\mathrm{C}=\mathrm{N}), 814 .{ }^{1} \mathrm{H}-\mathrm{NMR}(300 \mathrm{MHz}$, DMSO-d $\left.d_{6}\right): \delta 1.03\left(3 \mathrm{H}, \mathrm{t}, J=7.2 \mathrm{~Hz}, \mathrm{CH}_{3}\right), 2.37\left(2 \mathrm{H}, \mathrm{q}, J=7.2 \mathrm{~Hz}, \mathrm{CH}_{2}\right), 2.48(4 \mathrm{H}, \mathrm{t}, J=5.0 \mathrm{~Hz}$, piperazine $\left.\mathrm{CH}_{2}\right), 3.30\left(4 \mathrm{H}, \mathrm{t}, J=5.0 \mathrm{~Hz}\right.$, piperazine $\left.\mathrm{CH}_{2}\right), 6.99(2 \mathrm{H}, \mathrm{d}, J=8.9 \mathrm{~Hz}$, disubstituted $\mathrm{CH}), 7.17(1 \mathrm{H}, \mathrm{s}$, imidazole $\mathrm{CH}), 7.73-7.77(4 \mathrm{H}, \mathrm{m}$, disubstituted $\mathrm{CH},-\mathrm{HC}=\mathrm{CH}-), 7.87(2 \mathrm{H}, \mathrm{d}, J=8.8 \mathrm{~Hz}$, disubstituted $\mathrm{CH}), 7.91(1 \mathrm{H}, \mathrm{t}, J=1.3 \mathrm{~Hz}$, imidazole $\mathrm{CH}), 8.28(2 \mathrm{H}, \mathrm{d}, J=8.8 \mathrm{~Hz}$, disubstituted $\mathrm{CH}), 8.46(1 \mathrm{H}, \mathrm{s}$, imidazole CH). ${ }^{13} \mathrm{C}-\mathrm{NMR}\left(75 \mathrm{MHz}\right.$, DMSO- $\left.d_{6}\right): \delta=12.4,47.4,52.1,52.6,114.6,117.7,118.3,120.2,124.7$, $130.7,130.8,131.2,136.2,136.6,140.4,145.4,153.1,187.9$. ESI-MS [M + 2H] ${ }^{2+}: 194.20(100 \%)$.

1-(4-(1H-Imidazol-1-yl)phenyl)-3-(4-(4-(2-(dimethylamino)ethyl)piperazin-1-yl)phenyl)prop-2-en-1-one (3n): Yield: $78 \%$, M.P. $=146-149{ }^{\circ} \mathrm{C}$, FTIR $\left(\right.$ ATR, $\left.\mathrm{cm}^{-1}\right): 3036(\mathrm{C}-\mathrm{H}), 1655(\mathrm{C}=\mathrm{O}), 1300(\mathrm{C}=\mathrm{N}), 812 .{ }^{1} \mathrm{H}-\mathrm{NMR}$ $\left(300 \mathrm{MHz}, \mathrm{DMSO}-d_{6}\right): \delta 2.14\left(6 \mathrm{H}, \mathrm{s}, \mathrm{CH}_{3}\right), 2.33-2.44\left(4 \mathrm{H}, \mathrm{m}, \mathrm{CH}_{2}\right), 2.52(4 \mathrm{H}, \mathrm{t}, J=4.7 \mathrm{~Hz}$, piperazine $\left.\mathrm{CH}_{2}\right), 3.28\left(4 \mathrm{H}, \mathrm{t}, J=4.7 \mathrm{~Hz}\right.$, piperazine $\left.\mathrm{CH}_{2}\right), 6.97(2 \mathrm{H}, \mathrm{d}, J=8.9 \mathrm{~Hz}$, disubstituted $\mathrm{CH}), 7.16(1 \mathrm{H}, \mathrm{s}$, imidazole $\mathrm{CH}), 7.72-7.76(4 \mathrm{H}, \mathrm{m}$, disubstituted $\mathrm{CH},-\mathrm{HC}=\mathrm{CH}-), 7.86(2 \mathrm{H}, \mathrm{d}, J=8.7 \mathrm{~Hz}$, disubstituted $\mathrm{CH}), 7.91(1 \mathrm{H}, \mathrm{t}, J=1.2 \mathrm{~Hz}$, imidazole $\mathrm{CH}), 8.27(2 \mathrm{H}, \mathrm{d}, J=8.7 \mathrm{~Hz}$, disubstituted $\mathrm{CH}), 8.45(1 \mathrm{H}, \mathrm{s}$, imidazole $\mathrm{CH}) .{ }^{13} \mathrm{C}-\mathrm{NMR}\left(75 \mathrm{MHz}\right.$, DMSO- $\left.d_{6}\right): \delta=40.0,47.4,53.3,56.3,57.1,114.6,117.6,118.3,120.2$, $124.7,130.7,130.8,131.2,136.2,136.6,140.4,145.4,153.0,187.9$. ESI-MS [M + H] $]^{+}: 430.35$ (100\%).

1-(4-(1H-Imidazol-1-yl)phenyl)-3-(4-(4-(3-(dimethylamino)propyl)piperazin-1-yl)phenyl)prop-2-en-1-one (3o): Yield: 79\%, M.P. $=138-141^{\circ} \mathrm{C}$, FTIR $\left(\mathrm{ATR}, \mathrm{cm}^{-1}\right): 3086(\mathrm{C}-\mathrm{H}), 1655(\mathrm{C}=\mathrm{O}), 1339(\mathrm{C}=\mathrm{N}), 812 .{ }^{1} \mathrm{H}-\mathrm{NMR}$ $\left(300 \mathrm{MHz}, \mathrm{DMSO}-d_{6}\right): \delta 1.56\left(2 \mathrm{H}, \mathrm{p}, J=7.3 \mathrm{~Hz}, \mathrm{CH}_{2}\right), 2.10\left(6 \mathrm{H}, \mathrm{s}, \mathrm{CH}_{3}\right), 2.20\left(2 \mathrm{H}, \mathrm{t}, J=7.3 \mathrm{~Hz}, \mathrm{CH}_{2}\right), 2.31$ $\left(2 \mathrm{H}, \mathrm{t}, J=7.3 \mathrm{~Hz}, \mathrm{CH}_{2}\right), 2.47\left(4 \mathrm{H}, \mathrm{t}, J=4.8 \mathrm{~Hz}\right.$, piperazine $\left.\mathrm{CH}_{2}\right), 3.28\left(4 \mathrm{H}, \mathrm{t}, J=4.8 \mathrm{~Hz}\right.$, piperazine $\left.\mathrm{CH}_{2}\right)$, $6.97(2 \mathrm{H}, \mathrm{d}, J=8.9 \mathrm{~Hz}$, disubstituted $\mathrm{CH}), 7.16(1 \mathrm{H}$, s, imidazole $\mathrm{CH}), 7.70-7.76(4 \mathrm{H}, \mathrm{m}$, disubstituted $\mathrm{CH},-\mathrm{HC}=\mathrm{CH}-), 7.86(2 \mathrm{H}, \mathrm{d}, J=8.7 \mathrm{~Hz}$, disubstituted $\mathrm{CH}), 7.91(1 \mathrm{H}, \mathrm{t}, J=1.2 \mathrm{~Hz}$, imidazole $\mathrm{CH})$, $8.27(2 \mathrm{H}, \mathrm{d}, J=8.7 \mathrm{~Hz}$, disubstituted $\mathrm{CH}), 8.45(1 \mathrm{H}$, s, imidazole $\mathrm{CH}) .{ }^{13} \mathrm{C}-\mathrm{NMR}\left(75 \mathrm{MHz}, \mathrm{DMSO}-d_{6}\right)$ : $\delta=24.9,45.7,47.3,53.0,56.5,57.8,113.7,114.6,118.2,120.2,124.6,130.7,130.8,131.2,136.2,136.6,140.4$, 145.3, 153.0, 187.9. ESI-MS [M + H] $]^{+} 444.35$ (100\%).

\subsection{Antifungal Activity}

Microbiological studies were performed according to the EUCAST definitive (EDef 7.1) method [34] for C. albicans (ATCC 24433), C. krusei (ATCC 6258), C. parapsilosis (ATCC 22019), and C. glabrata (ATCC 90030). Fluconazole and ketoconazole were used as control drugs. Two MIC readings were carried out for each chemical agent. The yeasts were maintained in RPMI after overnight incubation at $37^{\circ} \mathrm{C}$. The inocula of test microorganisms was adjusted to match the turbidity of a MacFarland 0.5 standard tube as determined with a spectrophotometer, and the final inoculum size was $0.5-2.5 \times 10^{5} \mathrm{cfu} / \mathrm{mL}$ for the antifungal assay. Testing was carried out in $\mathrm{RPMI}$ at $\mathrm{pH}=7$, and the two-fold serial dilutions technique was applied. The last well on the microplates containing only inoculated broth was kept as a control, and the last well with no growth of microorganism was recorded to represent the $\mathrm{MIC}_{50}$ expressed in $\mu \mathrm{g} / \mathrm{mL}$. For the antifungal assays, the compounds were 
dissolved in DMSO. Further dilutions of the compounds and standard drugs in the test medium were prepared at the required quantities of $800,400,200,100,50,25,12.5,6.25,3.125,1.5625$, and $0.78 \mu \mathrm{g} / \mathrm{mL}$ concentrations RPMI. The completed plates were incubated for $24 \mathrm{~h}$. At the end of the incubation, resazurin $(20 \mu \mathrm{g} / \mathrm{mL})$ was added into each well to control the growth in the wells. Completed plates were incubated for $2 \mathrm{~h}$. MIC $_{50}$ values were determined using a microplate reader at $590 \mathrm{~nm}$ excitation and $560 \mathrm{~nm}$ emission. Each experiment in the antimicrobial assays was replicated twice in order to define the $\mathrm{MIC}_{50}$ values given in Table 1.

\subsection{Quantification of Ergosterol Level}

Extraction of total sterols from C. krusei was performed as recorded by Breivik and Owades [35]. Quantification of ergosterol level in this extract was carried out in accordance with our recently described method [36].

\subsection{Cytotoxicity Test}

Cytotoxicity was tested using the NIH/3T3 mouse embryonic fibroblast cell line (ATCC ${ }^{\circledR}$ CRL-1658 ${ }^{\mathrm{TM}}$, London, UK). NIH/3T3 cells were incubated according to the supplier's recommendations. $\mathrm{NIH} / 3 \mathrm{~T} 3$ cells were seeded at $1 \times 10^{4}$ cells into each well of the 96 -well plates. The MTT assay was performed as previously described [37,38]. The compounds were tested between 800 and $0.78 \mu \mathrm{g} / \mathrm{mL}$ concentrations. Inhibition \% was calculated for each concentration according to the formula below, and $\mathrm{IC}_{50}$ values were determined by plotting a dose-response curve of inhibition \% versus compound concentrations tested [39].

$$
\% \text { inhibition }=100-(\text { mean sample } \times 100 / \text { mean solvent })
$$

\subsection{Molecular Docking Studies}

A structure-based in silico procedure was applied to discover the binding modes of the most active compound $3 c$ to 14-alpha-sterol demethylase enzyme active sites. The crystal structure of the enzyme (PDB ID: 1EA1) [33], which was crystallized with the reference drug (fluconazole) of antifungal activity assay, was retrieved from the Protein Data Bank server (www.pdb.org).

The structure of the ligand was built using the Schrödinger Maestro [40] interface and was then submitted to the Protein Preparation Wizard protocol of the Schrödinger Suite 2016 Update 2 [41]. The ligands were prepared by LigPrep 3.8 [42] to assign the protonation states at $\mathrm{pH} 7.4 \pm 1.0$ and the atom types correctly. Bond orders were assigned and hydrogen atoms were added to the structures. The grid generation was formed using Glide 7.1 [43], and docking runs were performed with the standard precision docking mode (SP).

\section{Conclusions}

In the present study, 15 new imidazole compounds that incorporate chalcone pharmacophores as antifungal agents were designed and synthesized. Activity studies revealed the potency of Compounds 3a-3d as antifungal agents. Furthermore, toxicological study enhanced the biological importance of these compounds. Results of the ergosterol level quantification assay revealed that the mechanism of action of the compounds is related to the inhibition of the biosynthesis of ergosterol, a vital sterol regulating membrane fluidity, plasma membrane biogenesis, and function. The docking studies clearly explained the molecular interacting mode of Compound $3 \mathrm{c}$ in the active region of 14-alpha-sterol demethylase. Consequently, all of this information may pave the way for medicinal chemists to synthesize similar compounds that have enhanced antifungal profiles.

Supplementary Materials: The following are available online.

Acknowledgments: This study was financially supported by Anadolu University Scientific Projects Fund, Project No.: 1705 S183. 
Author Contributions: Y.O. and Z.A.K. conceived and designed the experiments; D.O. and B.K.Ç. performed the synthesis; S.L. performed analysis studies; B.N.S. and U.A.C. performed activity tests; B.N.S. performed docking studies; Ö.A. performed the toxicity tests; D.O., B.K.Ç., B.N.S., S.L., U.A.Ç., Ö.A., Y.O. and Z.A.K. wrote the paper.

Conflicts of Interest: The authors declare no conflict of interest.

\section{References}

1. Tang, H.; Wub, J.; Zhang, W.; Zhao, L.; Zhang, Y.H.; Shen, C.W. Design, Synthesis and Biological Evaluation of Novel Non-Azole Derivatives as Potential Antifungal Agents. Chin. Chem. Lett. 2015, 26, 1161-1164. [CrossRef]

2. Canuto, M.M.; Rodero, F.G. Antifungal Drug Resistance to Azoles and Polyenes. Infect. Dis. 2002, 2, $550-563$. [CrossRef]

3. Jiang, Z.; Gu, J.; Wang, C.; Wang, S.; Liu, N.; Jiang, Y.; Dong, G.; Wang, Y.; Liu, Y.; Yao, J.; et al. Design, synthesis and antifungal activity of novel triazole derivatives containing substituted 1,2,3-triazole-piperdine side chains. Eur. J. Med. Chem. 2014, 82, 490-497. [CrossRef] [PubMed]

4. Cast'on-Osorio, J.J.; Rivero, A.; Torre-Cisneros, J. Epidemiology of Invasive Fungal Infection. Int. J. Antimicrob. Agents 2008, 32, 103-109. [CrossRef]

5. Marchetti, O.; Bille, J.; Fluckiger, U.; Eggimann, P.; Ruef, C.; Garbino, J.; Calandra, T.; Glauser, M.P.; Tauber, M.G.; Pittet, D. Fungal Infection Network of Switzerland (FUNGINOS), Epidemiology of Candidemia in Swiss Tertiary Care Hospitals: Secular Trends, 1991-2000. Clin. Infect. Dis. 2003, 38, 311-320. [CrossRef] [PubMed]

6. Walsh, T.J.; Viviani, M.A.; Arathoon, E.; Chiou, C.; Ghannous, M.; Groll, A.H.; Odds, F.C. New targets and delivery systems for antifungal therapy. Med. Mycol. 2000, 38, 335-347. [CrossRef] [PubMed]

7. Epstein, J.B. Antifungal therapy in oropharyngeal mycotic infections. Oral Surg. Oral Med. Oral Pathol. 1990, 69, 32-41. [CrossRef]

8. Guida, R.A. Candidiasis of the oropharynx and esophagus. Ear Nose Throat J. 1988, 67, 832-840. [PubMed]

9. Warrilow, A.G.; Parker, J.E.; Kelly, D.E.; Kelly, S.L. Azole Affinity of Sterol 14 $\alpha$-Demethylase (CYP51) Enzymes from Candida albicans and Homo sapiens. Antimicrob. Agents Chemother. 2013, 57, 1352-1360. [CrossRef] [PubMed]

10. Lupetti, A.; Danesi, R.; Campa, M.; Del Tacca, M.; Kelly, S. Molecular basis of resistance to azole antifungals. Mol. Med. 2002, 8, 77-81. [CrossRef]

11. Moraca, F.; De Vita, D.; Pandolfi, F.; Di Santo, R.; Costi, R.; Cirilli, R.; D'Auria, F.D.; Panella, S.; Palamara, A.T.; Simonetti, G.; et al. Synthesis, biological evaluation and structureeactivity correlation study of a series of imidazol-based compounds as Candida albicans inhibitors. Eur. J. Med. Chem. 2014, 83, 665-673. [CrossRef] [PubMed]

12. Downer-Riley, N.K.; Jackson, Y.A. Recent Advances in the Synthesis of 1,3-Azoles. Curr. Top. Med. Chem. 2016, 16, 3617-3626. [CrossRef] [PubMed]

13. Zhang, H.Z.; Gan, L.L.; Wang, H.; Zhou, C.H. New Progress in Azole Compounds as Antimicrobial Agents. Mini Rev. Med. Chem. 2017, 17, 122-166. [CrossRef] [PubMed]

14. Kaplancikli, Z.A.; Turan-Zitouni, G.; Özdemir, A.; Revial, G. Synthesis and anticandidal activity of some imidazopyridine derivatives. J. Enzym. Inhib. Med. Chem. 2008, 23, 866-870. [CrossRef] [PubMed]

15. Reis, D.; Recio Despaigne, A.A.; Da Silva, J.G.; Silva, N.F.; Vilela, C.F.; Mendes, I.C.; Takahashi, J.A.; Beraldo, H. Structural Studies and Investigation on the Activity of Imidazole-Derived Thiosemicarbazones and Hydrazones against Crop-Related Fungi. Molecules 2013, 18, 12645-12662. [CrossRef] [PubMed]

16. Niimi, M.; Firth, N.A.; Cannon, R.D. Antifungal drug resistance of oral fungi. Odontology 2010, 98, 15-25. [CrossRef] [PubMed]

17. Boucher, H.W.; Groll, A.H.; Chiou, C.; Walsh, T.J. Newer systemic antifungal agents. Drugs 2004, 64, 1997-2020. [CrossRef] [PubMed]

18. Zhang, W.; Ramamoorthy, Y.; Kilıcarslan, T.; Nolte, H.; Tyndale, R.F.; Sellers, E.M. Inhibition of Cytochromes P450 by Antıfungal Imıdazole Derivatıves Drug Metabolısm And Disposition. DMD 2002, 30, 314-318. [CrossRef] 
19. Lopez, S.N.; Castelli, M.V.; Zacchino, S.A.; Domınguez, J.N.; Lobo, G.; Charris-Charris, J.; Corte, J.G.C.; Ribas, J.C.; Devia, C.; Rodriguezd, A.M.; et al. In Vitro Antifungal Evaluation and Structure-Activity Relationships of a New Series of Chalcone Derivatives and Synthetic Analogues, with Inhibitory Properties against Polymers of the Fungal Cell Wall. Bioorg. Med. Chem. 2001, 9, 1999-2013. [CrossRef]

20. Batovska, D.; Parushev, S.; Slavova, A.; Bankova, V.; Tsvetkova, I.; Ninova, M.; Najdenski, H. Study on the substituents' effects of a series of synthetic chalcones against the yeast Candida albicans. Eur. J. Med. Chem. 2007, 42, 87-92. [CrossRef] [PubMed]

21. Nowakowska, Z.; Kedzia, B.; Schroeder, G. Synthesis, physicochemical properties and antimicrobial evaluation of new (E)-chalcones. Eur. J. Med. Chem. 2008, 43, 707-713. [CrossRef] [PubMed]

22. Boecka, P.; Leala, P.C.; Yunesa, R.A.; Filhob, V.C.; Lopez, S.; Sortinoc, M.; Escalantec, A.; Furlanc, R.L.E.; Zacchinoc, S. Antifungal Activity and Studies on Mode of Action of Novel Xanthoxyline-Derived Chalcones. Arch. Pharm. Chem. Life Sci. 2005, 338, 87-95. [CrossRef] [PubMed]

23. Lahtchev, K.L.; Batovska, D.I.; Parushev, S.P.; Ubiyvovk, V.M.; Sibirny, A.A. Antifungal activity of chalcones: A mechanistic study using various yeast strains. Eur. J. Med. Chem. 2008, 43, 2220-2228. [CrossRef] [PubMed]

24. Borra, R.C.; Lotufo, M.A.; Gagioti, S.M.; Barros Fde, M.; Andrade, P.M. A simple method to measure cell viability in proliferation and cytotoxicity assays. Braz. Oral Res. 2009, 23, 255-262. [CrossRef] [PubMed]

25. Palomino, J.C.; Martin, A.; Camacho, M.; Guerra, H.; Swings, J.; Portaels, F. Resazurin microtiter assay plate: Simple and inexpensive method for detection of drug resistance in Mycobacterium tuberculosis. Antimicrob. Agents Chemother. 2002, 46, 2720-2722. [CrossRef] [PubMed]

26. Ozkay, Y.; Tunalı, Y.; Karaca, H.; Işıkdağ, I. Antimicrobial activity of a new series of benzimidazole derivatives. Arch. Pharm. Res. 2011, 34, 1427-1435. [CrossRef] [PubMed]

27. Bard, M.; Lees, N.D.; Turi, T.; Craft, D.; Cofrin, L.; Barbuch, R.; Koegel, C.; Loper, J.C. Sterol synthesis and viability of erg11 (cytochrome P450 lanosterol demethylase) mutations in Saccharomyces cerevisiae and Candida albicans. Lipids 1993, 28, 963-967. [CrossRef] [PubMed]

28. Gooday, G.W. Cell membrane. In The Growing Fungus; Chapman \& Hall: London, UK, 1995; pp. $62-64$.

29. Gollapudy, R.; Ajmani, S.; Kulkarni, S.A. Modeling and interactions of Aspergillus fumigatus lanosterol 14- $\alpha$ demethylase 'A' with azole antifungals. Bioorg. Med. Chem. 2004, 12, 2937-2950. [CrossRef] [PubMed]

30. Kramer, J.A.; Sagartz, J.E.; Morris, D.L. The application of discovery toxicology and pathology towards the design of safer pharmaceutical lead candidates. Nat. Rev. Drug Discov. 2007, 6, 636-649. [CrossRef] [PubMed]

31. International Organization for Standardization. Biological Evaluation of Medical Devices-Part 5: Tests for In Vitro Cytotoxicity ISO-10993-5, 3rd ed.; International Organization for Standardization: Geneva, Switzerland, 2009.

32. González-Chávez, R.; Martínez, R.; Torre-Bouscoulet, M.E.; Gallo, M.; González-Chávez, M.M. De novo design of non-coordinating indolones as potential inhibitors for lanosterol 14- $\alpha$-demethylase (CYP51). Chem. Pharm. Bull. 2014, 62, 16-24. [CrossRef] [PubMed]

33. Podust, L.M.; Poulos, T.L.; Waterman, M.R. Crystal structure of cytochrome P450 $14 \alpha$-sterol demethylase (CYP51) from Mycobacterium tuberculosis in complex with azole inhibitors. Proc. Natl. Acad. Sci. USA 2001, 98, 3068-3073. [CrossRef] [PubMed]

34. EUCAST. Definitive Document EDef 7.1: Method for the Determination of Broth Dilution MICs of Antifungal Agents for Fermentative Yeasts. Clin. Microbiol. Infect. 2008, 14, 398.

35. Breivik, O.N.; Owades, J.L. Spectrophotometric semi-microdetermination of ergosterol in yeast. Agric. Food Chem. 1957, 5, 360-363. [CrossRef]

36. Karaca Gençer, H.; Acar Çevik, U.; Levent, S.; Sağlık, B.N.; Korkut, B.; Özkay, Y.; Ilgın, S.; Öztürk, Y. New Benzimidazole-1,2,4-Triazole Hybrid Compounds: Synthesis, Anticandidal Activity and Cytotoxicity Evaluation. Molecules 2017, 22, 507. [CrossRef] [PubMed]

37. Sağlık, B.N.; Ilgın, S.; Özkay, Y. Synthesis of new donepezil analogues and investigation of their effects on cholinesterase enzymes. Eur. J. Med. Chem. 2016, 124, 1026-1040. [CrossRef] [PubMed]

38. Demir Özkay, Ü.; Can, Ö.D.; Sağlık, B.N.; Acar Çevik, U.; Levent, S.; Özkay, Y.; Ilgın, S.; Atlı, Ö. Design, synthesis, and AChE inhibitory activity of new benzothiazole-piperazines. Bioorg. Med. Chem. Lett. 2016, 26, 5387-5394. [CrossRef] [PubMed]

39. Patel, S.; Gheewala, N.; Suthar, A.; Shah, A. In-vitro cytotoxicity activity of Solanum nigrum extract against Hela cell line and Vero cell line. Int. J. Pharm. Pharm. Sci. 2009, 1, 38-46. 
40. Maestro, version 10.6; Schrödinger, LLC: New York, NY, USA, 2016.

41. Schrödinger, version 2016-2; LLC: New York, NY, USA, 2016.

42. LigPrep, version 3.8; Schrödinger, LLC: New York, NY, USA, 2016.

43. Glide, version 7.1; Schrödinger, LLC: New York, NY, USA, 2016.

Sample Availability: Samples of the compounds $\mathbf{3 a - 3 o}$ are available from the authors.

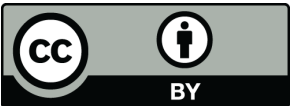

(C) 2018 by the authors. Licensee MDPI, Basel, Switzerland. This article is an open access article distributed under the terms and conditions of the Creative Commons Attribution (CC BY) license (http://creativecommons.org/licenses/by/4.0/). 